\title{
Severe Spinal Column Deformity from Scoliosis with Harrington Rods Implant
}

\author{
Hina Faisal ${ }^{*}$, Johnson $\mathrm{SN}^{2}$ and Gaber $\mathrm{AO}^{3}$ \\ ${ }^{1}$ Department of Surgery \& Critical Care, Houston Methodist Hospital, Houston, TX, USA \\ ${ }^{2}$ United States Anesthesia Partner, Houston Methodist Hospital, Houston, TX, USA \\ ${ }^{3}$ Department of Surgery \& Transplant Center, Houston Methodist Hospital, Houston, TX, USA
}

${ }^{*}$ Corresponding author: Hina Faisal, M.D., MRCS. Department of Surgery \& Critical Care, Houston Methodist Hospital, Houston, TX, USA; E-mail: hfaisal@houstonmethodist.org

Received: Auguest 05, 2020; Accepted: August 15, 2020; Published: August 20, 2020

Severe scoliotic deformity of the thoracolumbar spine imposes a significant anesthesia challenge for non-spine surgery. Patients with severe scoliosis are at increased risk for perioperative morbidity and mortality due to underlying pulmonary and cardiac dysfunctions [1-3]. Stress, pain, mechanical ventilation, and surgery-induced inflammation can further increase the risk of postoperative cardiopulmonary failure. We present a preoperative chest radiograph demonstrating extensive thoracolumbar scoliosis with Harrington rods implant, anatomic distortion, and bony dysmorphism (Panel A, white arrow). The patient underwent a living donor kidney transplant under general anesthesia. Preoperative anesthesia and surgical planning is crucial and should focus on airway difficulty, ventilation management, positioning, new kidney location, and postoperative pain management.

The kidney transplant is a heterotopic transplant surgery meaning the kidney is placed in a different location than existing kidneys. The new kidney is on the right or left side of the abdomen to allow the donor kidney to be easily anastomosed surgically to blood vessels and the bladder of the recipient. Due to the extensive deformity of the spinal column and right chest wall (Panel B, black arrow), the operation was performed in the left lateral decubitus position. Moreover, the donor kidney was placed to the right iliac fossa to decrease the risk of left lung atelectasis, restricted breathing, and sprinting from pain.
Ultrasound-guided quadratus lumborum was difficult in this patient due to atrophy of trunk muscles, chronic scarring, and artifacts from the implant, which required careful assessment of anatomical landmarks to perform a successful nerve block.

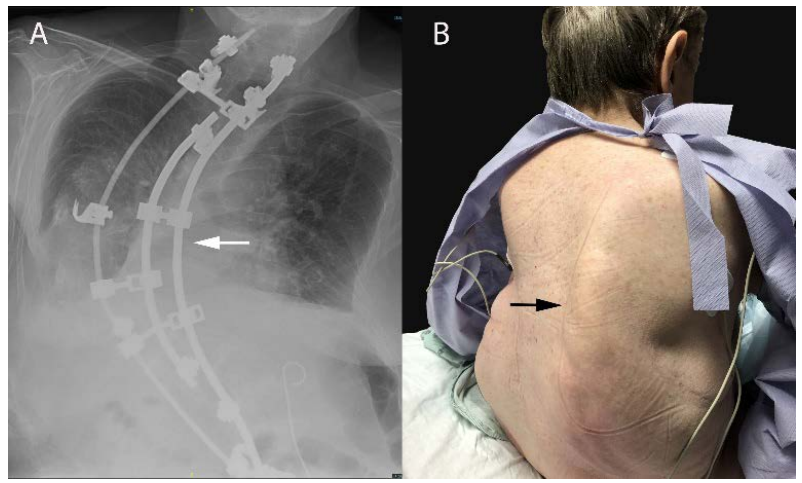

\section{References}

1. APA Bradford, David S, Tay B, Hu S (1999) Adult Scoliosis: Surgical Indications, Operative Management, Complications, and Outcomes. Spine 24: 2617-2629. [crossref]

2. Albert TJ, Purtill J, Mesa J, McIntosh T, Balderston RA (1995) Health outcome assessment before and after adult deformity surgery. A prospective study. Spine 20: 2002-2005. [crossref]

3. Kulkarni Anand H, Ambareesha M (2007) Scoliosis and anaesthetic considerations. Indian Journal of Anaesthesia. 51: 486-495

\section{Citation:}

Hina Faisal, Johnson SN and Gaber AO (2020) Severe Spinal Column Deformity from Scoliosis with Harrington Rods Implant. ARCH Women Health Care Volume 3(4): $1-1$. 